Research has demonstrated that the establishment of early intervention services within mental health organisations is an effective method of reducing the impact of psychosis on a young person's life. The research literature and available clinical practice guidelines describe key intervention areas that have an impact on the effectiveness of the early intervention service. These include: comprehensive assessment, social functioning, weight control, substance misuse and vocational recovery. Early intervention services can develop effective programmes to address these areas.

The occupational therapist can have a defined role in this setting, primarily across the three domains of assessment, intervention and advocacy. Effective assessment by an occupational therapist provides information on the occupational role functioning of a young person. Intervention services provide consultative and direct treatment to assist the young person in engaging in developmentally and culturally appropriate occupational roles. Advocacy involves educating members of the multidisciplinary mental health team about the role and potential outcomes of occupational therapy. By assessing, intervening and advocating for young people with early psychosis, individual therapists can contribute to developing a central role for occupational therapy in the field of early psychosis.

\title{
Early Psychosis: Treatment Issues and the Role of Occupational Therapy
}

\author{
Chris Lloyd, ${ }^{1}$ Geoff Waghorn, ${ }^{1}$ Philip Lee Williams, ${ }^{2}$ Meredith G Harris ${ }^{1}$ and Carina Capra ${ }^{3}$
}

\section{Introduction}

The benefits of early intervention for people who experience a first episode of psychosis have been reported in the literature for a number of years (Sanbrook et al 2003). Recent evidence from randomised controlled trials in Denmark and the United Kingdom (UK) has demonstrated more convincingly the superiority of specialised early intervention programmes over standard care, in terms of symptomatic outcomes, social functioning, vocational outcomes, family burden, engagement, and reduced

\footnotetext{
${ }^{1}$ The University of Queensland, Australia.

2 St Vincent's University Hospital, Dublin, Ireland.

${ }^{3}$ The Princess Alexandra Health Service District, Brisbane, Queensland, Australia.
}

Corresponding author: Dr Chris Lloyd, Senior Lecturer, Queensland Centre for Mental Health Research and the School of Population Health, The University of Queensland, Sumner Park BC, QLD 4074, Australia. Email: Lloyd@onthenet.com.au

Submitted: 18 December 2007

Accepted: 12 June 2008.

Key words: Mental health, early psychosis, intervention, occupational therapy. Reference: Lloyd C, Waghorn G, Williams PL, Harris MG, Capra C (2008) Early psychosis: treatment issues and the role of occupational therapy. British Journal of Occupational Therapy, 71(7), 297-304. inpatient care and treatment drop-out (Craig et al 2004, Jeppesen et al 2005, Petersen et al 2005, Thorup et al 2005, Garety et al 2006). Policy makers and health organisations have begun to react to the evidence and there are now an estimated 200 early intervention centres worldwide providing specialist intervention for this group of people (McGorry et al 2007).

Key areas of focus for early intervention services have been defined in several clinical practice guidelines and consensus statements (for example, National Early Psychosis Project Clinical Guidelines Working Party 1998, Bertolote and McGorry 2005, International Early Psychosis Association Writing Group 2005, McGorry et al 2005, Keshavan et al 2006). Early intervention is predicated on the assumption that it is possible to intervene during the course of the development of an illness in order to improve the prognosis and prevent the development of a full-blown disorder. Early intervention in psychosis encompasses three key areas:

1. The period prior to the onset of the psychosis, also known as the prodromal or ultra high risk period

2. The period prior to the initiation of treatment, also known as the duration of untreated psychosis

3. The provision of therapeutic interventions following the onset of the first episode of psychosis (Edwards et al 2005). 
This paper focuses on the last, post-onset period. It elaborates on the key areas of focus for early intervention services during this period, and considers the contribution of occupational therapy in enhancing the provision of effective care in first-episode psychosis.

In Australia, people with psychotic disorders who require ongoing treatment by public mental health services are typically managed by a case manager, who is a member of a multidisciplinary mental health team (Harvey and Fielding 2003). The case manager provides direct clinical interventions to the service user while also acting as a coordinator in relation to other service providers, both within the health sector and with external services such as housing and employment agencies (Rosen and Teesson 2001, Harvey and Fielding 2003). Although this model of care has obvious benefits in reducing the gaps in service for people with complex health needs, it has inhibited the development of discipline-specific roles (Lloyd et al 2002).

Occupational therapy has a long history of involvement in mental health care. As far back as the early 1920s, occupational therapists working in mental health services were using activity to engage people in productive occupational roles (Paterson 1997, Howe and Schwartzberg 2001). The professional knowledge and understanding of the occupational roles and the use of activity has grown remarkably since that time and there is now strong evidence supporting the practice of occupational therapy. In the emerging field of early intervention for people living with a psychotic disorder, the knowledge and skills of occupational therapy offer a unique and valuable asset to the intervention process.

\section{Developing services}

The potential benefits of early psychosis intervention include: reduced morbidity; more rapid recovery; better prognosis; the preservation of social skills, family and social supports; and a decreased need for hospitalisation (Edwards et al 2005). There are three key elements in the management of early psychosis: early recognition and assistance, initial assessment and treatment, and promoting recovery. Comprehensive programmes for the detection and treatment of early psychosis and to support the needs of young people with early psychosis carry the important function of promoting recovery, independence, equity and social self-sufficiency and facilitating the uptake of social, educational and employment opportunities (Bertolote and McGorry 2005). Despite robust evidence that specialised early intervention programmes are effective in the domains of symptomatic service utilisation and some functional outcomes (Killackey and Yung 2007), there remain some challenges including developing a greater focus on functional recovery and the prevention of relapse (McGorry et al 2007).

The International Early Psychosis Association Writing Group (2005) reported clinical guidelines for working with early psychosis, which incorporate a focus on these issues. A team of 29 invited international consultants contributed to the drafting and revision of the guidelines. The final draft was ratified by the Executive of the International Early Psychosis Association and was presented and formally endorsed at the Third International Conference held in Copenhagen in 2002. Table 1 briefly summarises elements of the guidelines relevant to this paper.

Table 1. Summary of relevant elements of the clinical guidelines, based on the International Early Psychosis Association Writing Group (2005)

The impact of the prodromal phase and the psychosis itself on the person, on the family and on developmental and vocational tasks should be determined. Strategies offered within a case management model may include supportive psychotherapy, with an active problem-solving orientation, and negotiating occupational pursuits, including employment and/or education. Families should be provided with ongoing support and information, wherever possible in a partnership that involves the person with psychosis, the family members and the treating clinicians.

Psychological and psychosocial treatments should be core elements in the critical period and should be used to assist the resolution of enduring positive and negative symptoms, the management of secondary morbidity and the promotion of recovery and positive mental health.

Recovery work should emphasise the need to find meaning and develop mastery in relation to the psychotic experience. Multi-family groups (with or without the person with psychosis present) that have a psychoeducation focus should be provided. Depression, suicide risk, substance misuse and social anxiety should be identified and treated actively. The side effects of antipsychotic medication, such as weight gain, sexual dysfunction and sedation, can retard recovery and should be monitored regularly. Antipsychotic medication reduces the risk of relapse in the early years after onset and should be considered as an essential basis for sustained recovery. Careful psychoeducation about the risks and possible manifestations of relapse should be provided, accompanied by frequent review and support and with unhindered access to early psychiatric treatment in the event of relapse. Early warning signs of relapse should be discussed with the person with psychosis and his or her family.

People with a psychosis should remain in comprehensive, multidisciplinary, specialist mental health care throughout the early phase of psychosis and, once their acute symptoms improve, not be discharged or transferred to primary care without specialist involvement (International Early Psychosis Association Writing Group 2005).

\section{Key areas of focus for early intervention services in first-episode psychosis}

\section{Psychosocial treatment}

Falloon et al (1998) discussed the basis for integrating biomedical, psychological and social strategies in the management of schizophrenia following a review of the literature. It was found that effective treatment components included psychoeducation, medication 
strategies, carer-based stress management training, community-based intensive treatment, living skills training, and specific drug and cognitive behavioural strategies for residual symptoms. They concluded that treatment for schizophrenia is best provided by integrating the various and specific psychosocial intervention strategies in addition to the optimal use of medication. Implementing these strategies includes the use of a comprehensive assessment and treatment plan, the training of mental health professionals and a periodic review with assessment packages.

Penn et al (2005) reviewed research on psychosocial treatment in first-episode psychosis. They found that comprehensive treatment approaches show promise in reducing symptoms and hospital readmissions, as well as in improving functional outcome. Penn et al (2005) concluded that adjunctive psychosocial interventions in early psychosis may be beneficial across a variety of domains and can assist with symptomatic and functional recovery.

\section{Treatment programmes}

Psychosocial interventions are a crucial component of relapse prevention in schizophrenia (Sanbrook and Harris 2003). De Haan et al (2003) described a treatment programme that was developed for young people admitted to their clinic if they had an Axis I diagnosis of schizophrenia or a related disorder. This was an intensive psychosocial and medication programme. The treatment involved pharmacotherapy, psychoeducation for service users and families, an individually oriented intervention for disease management, including recognition of early prodromal signs, stress management and medication management, as well as intensive support for structural activities (work or study), continuity of care and parent groups. The results from their study suggest that a delay in intensive psychosocial treatment may be a better predictor of negative symptoms at outcome than a delay in starting antipsychotic medication.

Fisher and Savin-Baden (2001) conducted a qualitative research project with participants of the TIME programme, which was developed by occupational therapists specifically for young people experiencing psychosis. Through the process of interpretation, three main themes were identified: the views of consumers, empowerment and access to information, and autonomy versus duty of care. O'Toole et al (2004) conducted a qualitative investigation to explore service users' experiences of a first-episode intervention. The main elements identified by the service users included the human approach as key to the recovery process: being involved in treatment decisions, the flexibility of appointments, a high nurse to patient ratio, a reduction in psychotic symptoms, increased confidence and independence, and the provision of daily structure. This study provides a service users' perspective on current best practice guidelines and lends qualitative support for government recommendations.
Albiston et al (1998) evaluated the impact of a group-based transitional psychosocial programme on recovery from a first episode of psychosis. The programme consisted of five streams: vocational, creative expression, social recreational, health promotion and personal development. The key elements of the recovery programme included: incorporation of the principles of recovery into the practice and structure of the group programme; an emphasis on the provision of a range of social environments; the active involvement of participants through the process of collaborative goal setting; basing the selection of group programmes on the types of goals of individuals; the establishment of a supportive relationship with a group programme staff member; and ensuring the age-appropriate content of groups. They suggested that involvement in the group programme may have had a positive impact on a subgroup of participants with a poor level of premorbid adjustment by providing a holding pattern in the critical period following the emergence of first-episode psychosis, and thus prevented deterioration and the development of disability.

\section{Social functioning}

Individuals presumed to be at risk for schizophrenia and people in their first episode to the illness demonstrate a significant impairment in social functioning across multiple domains. It is imperative to provide therapeutic interventions that address social functioning, for example, social skills training, individualised educational programmes, family psychoeducation and/or psychotherapy in order to help to reduce stress and improve functional outcome (Ballon et al 2007). Although people with first episodes of psychosis respond well to initial treatment, they frequently relapse and a substantial proportion of people develop persistent symptoms. Social and functional deterioration is also a marked feature of the early course of the illness.

Garety et al (2006) reported on an early psychosis service that was developed in the UK. This service, run by a multidisciplinary team, provided a mix of medication management, cognitive behavioural therapy, vocational input and family intervention. The emphasis of the whole programme was on helping the service user to retain or recover the functional capacity to return to study or work, to resume leisure pursuits and to retain or re-establish supportive social networks. A family and carer support group and a social activity programme were established. This study was one of the first UK randomised controlled trials to report the effects of an early intervention service. The results indicate that the provision of a specialist service for people early in the course of psychosis had a range of benefits. These included: superior social outcomes, at 18 months, in regaining or establishing social relationships, in time spent in vocational activity and in global functioning; it was more satisfactory for participants than generic services; and it led to a higher reported quality of life. There was also an increased contact with services and a reduction in hospitalisation, and fewer recorded incidents of adverse events taking 
place (for example, death, prison, homelessness, violence or self-harm).

\section{Weight control}

Various antipsychotic medications are associated with body weight gain. Strassnig et al (2007) recognised the significant health risks that are associated with being obese and decided that it was important to quantify the actual magnitude of weight gain that these medications induced. They examined the weight gain liabilities of various classic and novel antipsychotics in a large group of first-episode psychotic service users during their first year of treatment.

Their study demonstrated that first-episode service users treated with certain antipsychotics can gain much more weight than healthy controls and service users not receiving antipsychotics, placing them at a high risk to develop early obesity-associated comorbity. Olanzapine exposure for a year increases body weight in first-episode psychosis service users by almost a quarter over baseline weight, followed by risperidone and haloperidol. Although approximately two-thirds of service users treated with novel agents gain clinically significant amounts of weight, only one-third of those treated with classic antipsychotics do so. Younger service users and service users with more negative symptoms gain more weight when exposed to antipsychotics; also, a greater number of co-medications per service user, and co-presentation of antidepressants, independently worsen antipsychotic-associated weight gain. The authors suggested that a behavioural weight control programme be introduced as a preventative step at the commencement of pharmacotherapy.

\section{Substance misuse}

The rates of substance misuse in first-episode psychosis are high, with alcohol and cannabis being the most frequently used substances (McCleery et al 2006). Substance misuse has been associated with increased hospital admissions, more severe positive symptoms and poorer medication compliance. Wade et al (2006) examined the potential effects of substance misuse on inpatient admission and remission and the relapse of positive symptoms in first-episode psychosis. The results showed that substance misuse was independently associated with an increased risk of inpatient admission, the relapse of positive symptoms and a shorter time to relapse of positive symptoms. Substance misuse was not associated with remission or time to remission of positive symptoms. Heavy substance misuse was associated with an increased risk of inpatient admission, relapse and a shorter time to relapse. Wade et al (2006) concluded that substance misuse was an independent risk factor for a problematic recovery from first-episode psychosis.

\section{Vocational rehabilitation}

A key area affected by psychotic illness is vocational functioning. People with psychiatric disorders have lower rates of employment than other disability groups and, within this population, people with a psychotic illness are least often employed (Sainsbury Centre for Mental Health 2007). Psychosis has a peak onset in late adolescence and early adulthood, which is also when key developmental stages occur, such as the completion of education and training and the beginning of career pathways (Killackey et al 2006). Being employed is desirable for individuals with a psychotic illness because it leads to gain in several life domains. These include the areas influenced directly by being employed, such as receiving income, social contact and having an external time structure, as well as indirect consequences, such as increasing the quality of life, reducing hospitalisation, increasing efficacy in the management of illness, participating in the community, and having a productive and contributing social role (Lloyd and Waghorn 2007). The emerging evidence is that a highly individualised model of supported employment (Bond 2004, Porteous and Waghorn 2007, Killackey and Waghorn, in press) is even more effective in younger less vocationally disabled groups. However, there are challenges to implementing evidence-based vocational interventions for people with first-episode psychosis.

Bassett et al (2001) conducted a qualitative study to identify the issues experienced by young people diagnosed with psychosis wanting to gain employment. The study indicated that the young participants did not identify labour market opportunities or the lack of them as the most significant issue influencing their ability to gain employment. They identified a number of barriers that had an impact on their ability to achieve their goal of employment. The participants focused primarily on issues related to personal losses, low self-esteem, a lack of direction, stigma, difficulties in identifying and achieving life goals, treatment issues and the need for support. The researchers concluded that it was important to establish programmes to enable young people to have the opportunity to develop or enhance their skills in the areas of communication, self-confidence, time management and goal setting.

All community members have the right to work in suitable conditions. Young people with a mental illness are particularly disadvantaged when it comes to participating in vocational training and higher education and in seeking and maintaining employment. Lloyd and Waghorn (2007) identified a number of barriers to employment among people with a mental illness. These included such things as the direct impact of mental illness on the person, the nature of the labour market and the availability of suitable assistance, and the forms of stigma. They highlighted that vocational activities can contribute to the recovery process through work being perceived as a means of self-empowerment and through work promoting a sense of independent identity and self-esteem. Lloyd and Waghorn (2007) suggested that in order to facilitate vocational recovery, it is important to initiate conversations about work and education in the early stages of illness and recovery and to provide direct access to the best evidence-based employment and supported education services. 


\section{The role of occupational therapy}

Psychosis is a complex illness that can require multidisciplinary input to provide meaningful and effective interventions. The Department of Health (2001) has published its vision for mental health care focusing on recovery. It states that 'the mental health system must support people in settings of their own choosing, enable access to community resources including housing, education, work, friendships - or whatever they think is critical to their own recovery' (Department of Health 2001, p24). The College of Occupational Therapists (2006) outlined a strategy for occupational therapists working in mental health. This document provides a guiding philosophy to providing effective intervention. It is important for all practitioners working in this field to have an awareness of this strategy. Another important document addressing recovery is that of Shepherd et al (2008), who put together a policy paper on making recovery a reality. This paper provides a comprehensive overview of recovery.

The occupational therapy profession is primarily focused on recovery and developing functional abilities (Lloyd et al 2004). This remains the case in the field of early intervention for people living with a psychotic disorder. The difference between an occupational therapist's role in a general community mental health setting and an early intervention service is the increased knowledge and awareness of the developmental stages and assistance needs during adolescence and early adulthood.

The occupational therapist's role is to provide information and direction to the service user, carers and, treating team with regard to any factors that will influence the recovery or development of functional abilities. This role can be broken down into the three domains of assessment and treatment planning, intervention and advocacy. An occupational therapist working under a case management model wears two hats: as a case manager and as an occupational therapist. This article discusses the occupational therapy specific role and does not examine the role of an occupational therapist in providing generic case management services.

\section{Assessment and treatment planning}

The key role of occupational therapy in assessment is to gain an understanding of a service user's occupational role history (what he or she used to do); his or her current occupational roles (what he or she does now); and his or her future or desired occupational roles (what he or she wants to do in the future). Current occupational role functioning is assessed against normal occupational roles for the person's culture and age. A comprehensive assessment identifies any discrepancies between the current and the past and/or future occupational roles of a person. It will also identify why these discrepancies exist and guide the treatment planning process.

The majority of people experiencing a first episode of psychosis are usually at the age near to the transition point from late adolescence to young adulthood. The typical occupational roles at this point include: engaging in vocational pursuits (work or study); social (establishing new or maintaining social networks); independence (establishing financial and/or emotional independence from parents); and leisure (engaging in leisure pursuits chosen by the individual). This list is by no means exhaustive and it is important to remember that everyone matures at a different pace and will have different needs. The role of the occupational therapist is to identify the occupational roles that are significant for the individual and to assist him or her to engage or re-engage in these roles. This includes occupational roles that are strengths (supportive of the recovery process) and weaknesses (roles that are not supportive of the recovery process).

People who are recovering from a first-episode psychosis face specific and complex issues that are related to their illness and treatment experiences, such as the appraisal of the extent of their recovery and the risk of relapse. Chen et al (2005) developed the Psychosis Recovery Instrument (PRI), which was designed to address specifically a number of closely related issues that are faced by people who are recovering from a first-episode psychosis. The process of development of the PRI involved the generation of items from qualitative interviews, the construction and refinement of these items and a validation study. The PRI consists of 25 items, with each item consisting of a declarative statement to which a six-point Likert scale is applied, ranging from 1 (strongly disagree) to 6 (strongly agree). It consists of three major domains, these being attitude to illness, attitude to treatment, and perception of recovery and relapse. The validation study showed that the PRI has a good test-retest reliability, internal consistency and convergent validity. The researchers suggest that this low burden, self-administered scale can be applied in clinical and research settings in order to obtain reliable information on the attitudes of service users on a range of interrelated issues in the recovery stage following a first-episode psychosis.

Models of care developed by the occupational therapy profession, such as the Model of Human Occupation (Kielhofner and Forsyth 1997) which is perhaps the most widely used in mental health, provide a good framework from which to explore the occupational role performance of individuals. From the assessment process, the occupational therapist feeds information back to the treating team regarding the factors that influence the successful completion of healthy occupational roles. These include factors such as the external environment, space, time, the occupational performance components and the core elements of occupational performance.

\section{Intervention}

The global aim of the intervention plan is to assist individuals to regain or engage in meaningful life roles at the point of a first psychotic episode. It has been demonstrated that engagement in meaningful occupations has a significant impact on a person's health (Minato and Zemke 2004). 
Minato and Zemke (2004) also stated that as well as engaging in meaningful roles, it is important to have a suitable balance between the occupational performance areas of self-care, rest, productivity and leisure (or the commercial equivalent of work, rest and play). The occupational therapist's role in the intervention phase is to provide consultative advice to the treating team about individual and group therapy in order to improve a consumer's ability to engage in his or her chosen occupational roles.

It is the role of the occupational therapist to provide information and individual treatment to address healthy occupational role performance, use of activity and adaptive techniques for identified weaknesses to improve occupational role performance. It is important that treatment advice is based on evidence from the assessment process and fits with the development phase of the service user.

The long history of occupational therapy in the provision of group therapy in the mental health setting ideally suits the occupational therapist to establishing and running group therapy programmes (Finlay 1997). The aim of occupational therapy groups is to provide opportunities for service users to engage in activities (that support their desired occupational roles, such as friend or peer group member) and develop skills and confidence (specific to occupational roles, such as boyfriend, worker or independent member of society) to enable them to perform occupational roles appropriate for their age and culture within 'normal' society.

Developing effective group programmes for people experiencing a first episode of psychosis is challenging. Lloyd et al (2005) reported findings that there was a strong social stigma both from the community and internally from the consumer with regard to mental illness. Service users engaging for the first time with the mental health service often avoid engaging with the service for this reason. Establishing environments that are normalised and supportive of the youth culture is important. Service users' needs are changing rapidly in this area owing to their stage of life and recovery progress (McDonald et al 2005). They often return to full-time work within the first 6 months of treatment. Occupational therapists need to be adaptable and flexible with regard to group structure, environment, time (after hours) and content.

\section{Advocacy}

Early intervention is a developing area of specialty for occupational therapy. There is little written information about the role of an occupational therapist in this setting. An important role is educating all disciplines in a multidisciplinary team and the community about what occupational therapy can offer in this setting. This can be done during case review meetings, through informal or formal education sessions and through demonstrating effective work practice. The authors of this paper believe that occupational therapists must market their abilities to the community to establish their role solidly. In most areas, the occupational therapy role will not be well defined and so it will fall to the individual occupational therapist to outline his or her role clearly and to explain this to other members of the service and the community. An important aspect of advocacy in the current culture of health is demonstrating outcomes either clinically or statistically.

\section{Implications for service delivery}

This article draws together a weight of evidence that identifies the need for specialist intervention for people experiencing a first-episode psychotic disorder. This evidence strongly supports the requirement to develop specialised early intervention services. Services must be properly staffed and funded to establish treatment services capable of meeting the needs of young people in order to reduce the long-term impact that psychosis has on functioning. Mental illness is the highest cause of years lost due to disability in Australia (Beggs et al 2007). Early intervention is a key to beginning to decrease the disability burden of psychotic disorders.

At the macro level, action is required to develop state-wide policies that support the implementation of effective early psychosis intervention programmes; staff and fund these services appropriately in order to enable them to meet the treatment needs as described above; review the policy of using a case management model in mental health services in order to utilise the discipline-specific skills that each professional groups adds to the multidisciplinary team; and establish and implement policy to implement effective early detection programmes.

Health services that are currently working with youth who are experiencing a psychotic disorder also have a role to play in establishing effective treatment programmes. At the health service level, individual clinicians and teams are required to establish a clear vision for establishing evidence-based interventions for treating psychotic disorders. A summary of the major components is provided in this article; however, services should also review the individual needs of the consumers in their district. Services are then required to advocate strongly for appropriate resources and funding to implement their plan. In the current climate of evidence-based funding, it is essential that services present a clear and logical argument to service managers for the development of these services. Key considerations should include the physical resources (space, financial, utilities and transport), human resources (motivated and enthusiastic staff and knowledge of area) and managerial support.

The individual occupational therapist can act as a key driver of change in establishing effective intervention for people living with a psychotic disorder by establishing an evidence-based argument as to the need for early intervention services. It is important for occupational therapists to regain their discipline-specific focus in this area and to demonstrate that they can provide specialised assessment and intervention programmes. Occupational therapists will need to define and market their role within 
the teams in which they work. Occupational therapists have the skills to look at functional and role changes for young people that often occur during the transitioning into young adulthood. Completing an assessment that focuses on the change in functional skills affecting occupational roles can act as a way to help with early detection, build resilience and enhance the maintenance of occupational roles. Improvement in functional skills and the identification of occupational roles are key outcomes to improved mental health outcomes.

\section{Conclusion}

Occupational therapists bring a unique skill set to the field of early intervention, with the evaluation of occupational roles and functional skills appropriate to the developmental age of young people with a psychotic illness. They have an increasingly important role in the field of early intervention, especially in addressing changes in occupational roles that could place young people at risk of social, occupational and psychological decline. Specialist assessment and intervention are provided, which enable service users to engage in developmentally and culturally appropriate occupational roles. Functional assessments are undertaken, thus contributing information to the interdisciplinary team's understanding of young people with psychosis. Occupational histories, including information about past and present occupation, interests, skills, community resources and supports, are gathered. It is essential that the role of the occupational therapist is added to that of the other professional groups to establish evidence-based treatment programmes that intervene effectively for the key areas discussed in this article.

\section{References}

Albiston DJ, Francey SM, Harrigan SM (1998) Group programmes for recovery from early psychosis. British Journal of Psychiatry, 172, 117-21.

Ballon JS, Kaur T, Marks II, Cadenhead KS (2007) Social functioning in young people a risk for schizophrenia. Psychiatry Research, 151(1-2), 29-35.

Bassett J, Lloyd C, Bassett H (2001) Work issues for young people with psychosis: barriers to employment. British Journal of Occupational Therapy, 64(2), 66-72.

Begg S, Vos T, Barker B, Stevenson C, Stanley L, Lopez A (2007) The burden of disease and injury in Australia in 2003. AlHW, Canberra. Available at: http://www.aihw.gov.au/search.cfm/criteria/burden\%20of\%20disease Accessed on 27.05.07.

Bertolote J, McGorry P (2005) Early intervention and recovery for young people with early psychosis: consensus statement. British Journal of Psychiatry, 187, Suppl. 48, S116-19.

Bond GR (2004) Supported employment: evidence for an evidence-based practice. Psychiatric Rehabilitation Journal, 27(1), 345-59.

Chen EYH, Tam DKP, Wong JWS, Law CW, Chui CPY (2005) Self-administered instrument to measure the patient's experience of recovery after first-episode psychosis: development and validation of the Psychosis Recovery Instrument. Australian and New Zealand Journal of Psychiatry, 39(6), 493-99.
College of Occupational Therapists (2006) Recovering ordinary lives. The strategy for occupational therapy in mental health services 2007-2017. A vision for the next ten years. London: COT.

Craig TKJ, Garety P, Power P, Rahaman N, Colbert S, Fornells-Ambrojo M, Dunn G (2004) The Lambeth Early Onset (LEO) Team: randomised controlled trial of the effectiveness of specialised care for early psychosis. British Medical Journal, 329(7474), 1067-70.

De Haan L, Linszen DN, Lenior ME, de Win ED, Gorsira R (2003) Duration of untreated psychosis and outcome of schizophrenia: delay in intensive psychosocial treatment versus delay in treatment with antipsychotic medication. Schizophrenia Bulletin, 29(2), 341-48.

Department of Health (2001) The journey to recovery - the Government's vision for mental health care. London: Department of Health Publications.

Edwards J, Harris MG, Bapat S (2005) Developing services for first-episode psychosis and the critical period. British Journal of Psychiatry, 187, Suppl. 48, S91-97.

Falloon IRH, Held T, Roncone R, Coverdale JH, Laidlaw TM (1998) Optimal treatment strategies to enhance recovery from schizophrenia. Australian and New Zealand Journal of Psychiatry, 32(1), 43-49.

Finlay L (1997) Groupwork. In: J Creek, ed. Occupational therapy and mental health. 2nd ed. London: Churchill Livingstone, 231-49.

Fisher A, Savin-Baden M (2001) The benefits to young people experiencing psychosis, and their families, of an early intervention programme: evaluating a service from the consumers' and providers' perspectives. British Journal of Occupational Therapy, 64(2), 58-65.

Garety PA, Craig TKJ, Dunn G, Forneslls-Ambrojo M, Colbert S, Rahaman N, Reid J, Power P (2006) Specialised care for early psychosis: symptoms, social functioning and patient satisfaction. British Journal of Psychiatry, 188(1), 37-45.

Harvey CA, Fielding JM (2003) The configuration of mental health services to facilitate care for people with schizophrenia. Medical Journal of Australia, 178(9), Suppl. 5, S49-52.

Howe M, Schwartzberg S (2001) A functional approach to group work in occupational therapy. Philadelphia: Lippincott Williams and Wilkins.

International Early Psychosis Association Writing Group (2005) International clinical practice guidelines for early psychosis. British Journal of Psychiatry, 187, Suppl. 48, S120-24.

Jeppesen P, Petersen L, Thorup A, Abel M, Øehlenschlæger J, Christensen TO, Krarup G, Hemmingsen R, Jorgensen P, Nordentoft M (2005) Integrated treatment of first-episode psychosis: effect of treatment on family burden: OPUS trial. British Journal of Psychiatry, 187, Suppl. 48, S85-90.

Keshavan MS, Roberts M, Wittmann D (2006) Guidelines for clinical treatment of early course schizophrenia. Current Psychiatry Reports, 8, 329-34.

Kielhofner G, Forsyth K (1997) The Model of Human Occupation: an overview of current concepts. British Journal of Occupational Therapy, 60(3), 103-10.

Killackey E, Young A (2007) Effectiveness of early intervention in psychosis. Current Opinion in Psychiatry, 20(2), 121-25.

Killackey $\mathrm{E}$, Waghorn $\mathrm{G}$ (in press) The challenge of integrating employment services with public mental health services in Australia: progress at the first demonstration site. Psychiatric Rehabilitation Journal.

Killackey EJ, Jackson HJ, Gleeson J, Hickie IB, McGorry PD (2006) Exciting career opportunity beckons! Early intervention and vocational rehabilitation in first-episode psychosis: employing cautious optimism. Australian and New Zealand Journal of Psychiatry, 40(11-12), 951-62 
Lloyd C, Waghorn G (2007) The importance of vocation in recovery for young people with psychiatric disabilities. British Journal of Occupational Therapy, 70(2), 50-59.

Lloyd C, King R, Bassett H (2002) A survey of Australian mental health occupational therapists. British Journal of Occupational Therapy, 65(2), 88-96.

Lloyd C, Tse S, Bassett H (2004) Mental health recovery and occupational therapy in Australia and New Zealand. International Journal of Therapy and Rehabilitation, 11(2), 64-70.

Lloyd C, Sullivan D, Williams PL (2005) Perceptions of social stigma and its effect on interpersonal relations in young males who experience a psychotic disorder. Australian Occupational Therapy Journal, 52(3), 243-50.

McCleery A, Addington J, Addington D (2006) Substance misuse and cognitive functioning in early psychosis: a 2 year follow-up. Schizophrenia Research, 88(1-3), 187-91.

McDonald E, Sauer K, Howie L, Albiston D (2005) What happens to social relationships in early psychosis: a phenomenological study of young people's experiences. Journal of Mental Health, 14(2), 129-43.

McGorry PD, Killackey E, Lambert T, Lambert M (2005) Royal Australian and New Zealand College of Psychiatrists clinical practice guidelines for the treatment of schizophrenia and related disorders. Australian and New Zealand Journal of Psychiatry, 39(1-2), 1-30.

McGorry PD, Killackey E, Yung AR (2007) Early intervention in psychotic disorders detection and treatment of the first episode and the critical early stages. Medical Journal of Australia, 187, Suppl. 7, S8-10.

Minato M, Zemke R (2004) Occupational choices of persons with schizophrenia living in the community. Journal of Occupational Science, 11(1), 31-39.

National Early Psychosis Project Clinical Guidelines Working Party (1998) Australian clinical guidelines for early psychosis. Melbourne: National Early Psychosis Project, University of Melbourne.

O'Toole MS, Ohlsen RI, Taylor TM, Purvis R, Walters J, Pilowsky LS (2004) Treating first episode psychosis - the service users' perspective: a focus group evaluation. Journal of Psychiatric and Mental Health Nursing, 11(3), 319-26.
Paterson CF (1997) A short history of occupational therapy in mental health. In: J Creek, ed. 2nd ed. Occupational therapy and mental health. London: Churchill Livingstone, 3-14.

Penn DL, Waldheter EJ, Perkins DO, Mueser KT, Lieberman JA (2005) Psychosocial treatment for first-episode psychosis: a research update. American Journal of Psychiatry, 162(12), 2220-32.

Petersen L, Nordentoft M, Jeppesen P, Øhlenschlæger J, Thorup A, Ostergaard C, Krarup G, Dahlstrom J, Haastrup B, Jorgensen P (2005) Improving 1-year outcome in first-episode psychosis. OPUS trial. British Journal of Psychiatry, 187, Suppl. 48, 598-103.

Porteous N, Waghorn G (2007) Implementing evidence-based employment services in New Zealand for young adults with psychosis: progress during the first five years. British Journal of Occupational Therapy, 70(12), 521-26.

Rosen A, Teesson M (2001) Does case management work? The evidence and the abuse of evidence-based medicine. Australian and New Zealand Journal of Psychiatry, 35(6), 731-46.

Sainsbury Centre for Mental Health (2007) Mental health and employment. London: Sainsbury Centre for Mental Health.

Sanbrook M, Harris A (2003) Origins of early intervention in first-episode psychosis. Australasian Psychiatry, 11(2), 215-19.

Sanbrook M, Harris A, Parada R, Young P (2003) The effectiveness of an early intervention team in the treatment of first episode psychosis. Australian e-Journal for the Advancement of Mental Health, 2(1).

Shepherd G, Boardman J, Slade M (2008) Making recovery a reality. London: Sainsbury Centre for Mental Health.

Strassnig M, Miewald J, Keshavan M, Gangulii R (2007) Weight gain in newly diagnosed first-episode patients and healthy comparisons: one-year analysis. Schizophrenia Research, doi: 10.1016/j.schres.2007.02.024

Thorup A, Petersen L, Jeppesen P, Øhlenschlæger J, Christensen TO, Krarup G, Jorgensen P, Nordentoft M (2005) Integrated treatment ameliorates negative symptoms in first episode psychosis - results from the Danish OPUS trial. Schizophrenia Research, 79(1), 95-105.

Wade D, Harrigan S, Edwards J, Burgess PM, Whelan G, McGorry PD (2006) Substance misuse in first-episode psychosis: 15-month prospective follow-up study. British Journal of Psychiatry, 189(3), 229-34.

\section{British Journal of Occupational Therapy Online}

